\title{
Organizational and Methodological Aspects of Monitoring the Implementation of the Business Process Automation Strategy
}

\author{
Vera T. Grishina ${ }^{1 *[O R C I D}$ 0000-0003-1307-8360], \\ Oksana G. Bondarenko 2[ORCID 0000-0002-6983-1764], \\ Vladimir A. Trifonov ${ }^{3[0000-0003-2815-3749]}$
}

\author{
${ }^{1}$ LEONOV Moscow Region University of Technology, Korolev, Russia \\ ${ }^{2}$ Belarusian Trade and Economics University of Consumer Cooperatives, Gomel, the Republic of Belarus \\ ${ }^{3}$ Yaroslav-the-Wise Novgorod State University, Veliky Novgorod, Russia \\ veragrishinat@mail.ru
}

\begin{abstract}
The material of the article reflects the results of a study that continued research work (R\&D) devoted to the participation of consumer cooperation trade in ensuring food security in the Republic of Belarus and carried out through the Belarusian Republican Foundation for Fundamental Research on a competitive basis. The authors have prepared proposals for a strategy for the formation of an optimal complex infrastructure for rural trade in Belarus for 2021-2025, which are implemented in the activities of business entities as part of the research. One of them is the comprehensive automation of the activities of trade, mainly rural, consumer cooperation organizations in Belarus. Automation is designed to ensure the application of network principles of trade organization in order to improve the performance of trade enterprises and the level of consumer satisfaction. The important tasks here are for monitoring the automation of business processes, which must be effectively organized. The purpose of the study is to develop measures to increase the level of achievability of the results of the strategy for automating business processes in the trade industry of consumer cooperation on the example of Belarus. The tasks and main results of the study are related to the development of measures for monitoring the automation of the activities of cooperative trade organizations in Belarus, approbation of some stages of monitoring and assessment of their effectiveness. The article demonstrates the applicability and effectiveness of the author's methodology for monitoring the implementation of the strategy for automating business processes in cooperative trade, outlines proposals for the practical use of the obtained monitoring results. The scientific significance of the research results lies in the development of scientific approaches to the organization of monitoring the implementation of the strategy for automating business processes, carried out in order to obtain analytical material for the development and adoption of managerial decisions to adjust the implementation of the strategy.
\end{abstract}

Keywords: strategy, strategy implementation, consumer cooperation, trade organizations, automation, business processes, software product

\section{INTRODUCTION}

The problems of implementing the strategy of organizations were studied by A.A. Bykov, D.V. Valovoy, E.I. Velesko, O.S. Vikhansky, I.N. Gerchikova, Z. Drazhek, A.I. Naumov, A.G. Porshneva, Z.P. Rumyantseva, N.A. Solomatin and others [1-5]. The authors considered the stages of implementing the strategy of the organization's activities in strategic management, the rules for the successful implementation of the strategy, the organizational structures of strategic management, studied the organizational culture as an object of strategic changes, and examined the experience of implementing the strategies. However, the issues of methodological support of monitoring as a tool for 
implementing the organization's strategy are not sufficiently represented in the literature.

\section{MATERIALS AND METHODS}

At the same time, measures to increase the level of achievability of the results of the implemented strategy, first, monitoring are of high scientific and practical significance and serve as information support for at least two management functions.

The purpose of the study is to develop a methodology for monitoring the implementation of a strategy for automating business processes in the trade industry of consumer cooperation on the example of Belarus.

Tasks:

- justify the sequence of actions to monitor the implementation of the strategy;

- provide a description of the implementation and results of a number of monitoring stages;

- demonstrate the application of the monitoring results in the management practice of the regional divisions of Belcoopsoyuz.

The article is written on the results of approbation of the author's methodology for developing a strategy for the formation of an integrated infrastructure for rural trade, which are reflected in the plan of measures of the strategy for a conceptual draft strategy for the formation of an optimal integrated infrastructure for rural trade in Belarus for the period up to 2025 [6].

The sources of information were also the materials obtained by the authors for monitoring the implementation of the strategy for automating business processes of 273 retail outlets (33\% of the assignment for 2021) and 52 warehouses (18\% of their total number). Registration, traditional content analysis of interviews and documents were used as methods of collecting information.

The commissioned nature of the study provided wide access to information sources, which made it possible to avoid possible methodological limitations and undesirable influence on the validity of the conclusions.

The commissioned nature of the study provided wide access to information sources, which made it possible to avoid possible methodological limitations and undesirable influence on the validity of the conclusions.

\section{RESULTS}

In modern conditions, various spheres of human activity involve the mandatory use of computer technology and the creation of information systems of varying complexity and functionality. Information processing in these systems has become an independent scientific and technical direction.

Information system is a set of data banks, information technologies and a complex (complexes) of software and hardware [7].

Corporate information system is an information system, the participants of which can be a limited number of persons, determined by its owner or by agreement of the participants in this information system.

An integrated automated system for managing the activities of an organization is an information and analytical system designed to automate management processes and covering all aspects of the economic activity of an entity [8].

In this case, the top management of the organization must have information for the analysis of economic activities, strategic planning, and forecasting. Ordinary employees should be provided with effective tools for making day-to-day decisions in carrying out their job duties [9].

It is believed that the success of the implementation of the chosen strategic direction of the organization's development is determined by the observance of the following rules [1]:

- availability of a plan for the implementation of the strategy in the form of targets,

- implementation of the strategy implementation plan,

- communicating goals, strategies and plans to employees to involve them in the process of implementing strategies,

- fixing the achievement of the goal,

- the timeliness of ensuring the receipt of the resources necessary for the implementation of the strategy.

The logical sequence of the above rules can be taken as the basis for a list of actions to monitor the implementation of the strategy for automating business processes in cooperative trade organizations in Belarus. The implementation of three key of these actions is demonstrated below. 
The studied strategy of consumer cooperation in Belarus is aimed at the development of digitalization until 2025 and the unity of approaches to automating business processes in all areas of its activity. In recent years, an active search for an optimal corporate information system for managing business processes has been carried out here. The software products used for information processing were in turn the following: the "Automated workstation of a commodity merchant", "1C: Enterprise", "Merchant", SAP, "Supermag +", etc. However, the variety of fragmentarily used software products does not allow complex automation of activities. In December 2019, the Board of Belcoopsoyuz decided to ensure the automation of the trading network with the ability to operate trade and distribution warehouses and retail facilities in a single database. Ls Trade Fusion ERP was chosen as a business process automation program.

Ls Trade Fusion ERP is a Belarusian software product for automating processes in trade, including in large retail chains and distribution warehouses, developed on the Ls Fusion platform in 2013. It serves for the implementation of projects with complex business logic, large amounts of information and quantity users [10].

Ls Fusion is a free open platform for information systems development based on the fifth-generation language of the same name. The creation of the Ls Fusion business application development platform was started in 2009 by NTO LuxSoft.

Thus, Ls Trade Fusion ERP is a fairly "young" software product. It is not presented in the data of the analytical center TAdviser, which since 2005 has been analyzing information on the development of the ERP systems market in Russia and in the world (Figure 1, Figure 2).

However, more than half of large retail Fast Moving Consumer Goods chains in Belarus use Ls Fusion ERP to manage their processes (Vitalur, Hippo, Neighbors, Santa, Island of Purity, Belmarket, Belkoopsoyuz, DorORS, etc.). Configurations of the trading system for Fashion (Mothercare, Next, Terranova, Calliope, etc.), pharmacy business (Tishas, Medway, Florafarm, etc.) have been designed and implemented, custom designs for the National Library of Belarus, "Svitanok" company, etc.

The assessment of the compliance of a software product with the requirements for integrated automation systems of a trade organization is of primary importance in monitoring the automation strategy, and this has become one of the subjects of research. The list of these requirements is as follows: functional requirements; reflection of the specifics of the business; ease of transition to another system; the ability to generate complete and versatile reporting; continuity of data from previous systems.

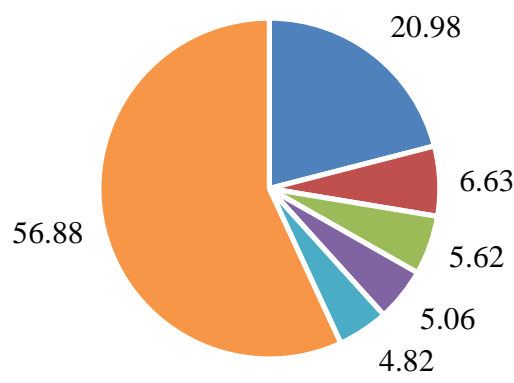

- 1C: Enterprise 8.0

- Galaxy ERP

- SAP ERP

- 1C: Enterprise 8.2

- 1C: ERP Enterprise Management 2.0

n Others

Figure 1. Systems by the number of implementation projects (ERP) in Russia and in the world throughout history

Source: [11]

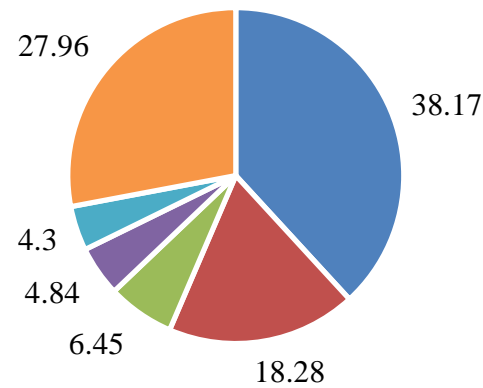

- 1C: ERP Enterprise Management 2.0

- Directum RX

- Microsoft Dynamics 365

- SAP S/4HANA

- $1 \mathrm{C}$ : Enterprise 8.3

- Others

Figure 2. Systems by the number of implementation projects (ERP) in Russia and in the world in 2020 Source: [11]

Compliance with the requirements for the integrated automation system of trade organizations 
of consumer cooperation was studied through solving such problems as demonstrating the functionality of the Ls Fusion ERP Trading System and justifying its advantages.

The functional purpose of the Ls Fusion ERP Trading System is represented by the corresponding modules (a software product that implements a set of functions that make up a single whole): management of a trading object; trade equipment management; formation and accounting of orders; procurement management; management of gift certificates; sales management; management of mutual settlements; calculation of marketing payments; own production; foreign economic activity; order picking; transport management; analytical reports; business analytics; integration services; custom development.

The main functionality of the "Trade Object Management" module can be presented as follows.

The "Purchases" function is intended for conducting operations with documents for purchase (documents-grounds, invoices, powers of attorney), drawing up reports on payments on documentsgrounds, on purchased material values and services.

The "Warehouse" function is designed to automate the accounting of the movement of material assets in the warehouses of the enterprise. This mode contains 7 reporting forms (register of movements, commodity report, report on containers, report on balances, report on goods turnover, by suppliers, report on operations)

The "Sales" function ensures interaction with partners when performing operations for the sale of goods and the provision of services. This mode contains 8 reporting forms (sales register, order execution, sales by week, sales report, sales to customers by weeks, sales by lots, sales register by lots, turnover by suppliers).

The function "Retail" provides accounting of goods in the process of sale through a retail trade network with the formation of the following reporting forms: report on stores; register of checks; reports on checks; register of lines of the check; ABC-analysis, which allows building a rating of sales by goods, considering their contribution to the total amount of sales - by revenue, and considering the income received - by income. At the same time, the stability of sales is also considered (XYZanalysis).

Thus, the functionality of the Ls Trade Fusion ERP program completely solves the tasks of a trade enterprise, for example, a retail one:
- study of consumer demand for goods, taking into account their purchasing power;

- definition of assortment policy;

- formation and regulation of the processes of supply and sale of goods in retail facilities;

- ensuring the turnover of material and labor resources.

The key advantage of the Ls Fusion ERP Trading System is the unification of business process management. Unification is a way to standardize the process and, consequently, to improve the quality of customer service, increase labor productivity, indicators of the organization's performance [12].

The main direction of unification of the management of business processes in consumer cooperation is expressed by the automation of the processes of its economic activity and accounting by a software product of the diverse nature of the activity of consumer cooperation (trade, public catering, procurement, production, automotive industry, etc.), which has differences in management, requiring different approaches to automation, and, consequently, significant improvement of the software.

The use of a single software product for automating the industries of the consumer cooperation system in the long term unifies the management of the main business processes that generate the organization's income (procurement, logistics, calculations, analytics, etc.), business management processes.

One of the aspects of the unification of business process management in Ls Trade Fusion ERP is the identity of the work algorithm in the software product modules that implement business processes through their functionality in the following areas:

1) implementation of all elements of business process management (planning, implementation and control);

2) unification of document flow in form and content - uniformity of the composition and forms of management documents in order to increase the efficiency and quality of management decision-making;

3) uniformity of the algorithm for documenting business transactions according to the principle each "subsequent document is based on the previous one"; 
4) a single software interface, a single main menu of the program. The easier it is to navigate the system, the more convenient it is to use it.

There are other advantages of the Ls Fusion ERP Trading System:

1) Versatility. Trading systems are prioritized for a specific trading facility (hypermarket, pharmacy, shoe store). As a rule, customization of a software product for a specific client complicates maintenance. On the Ls Fusion platform, business applications are developed by describing business logic, and not by writing program code.

2) The ability to work effectively in the "cloud" with many devices and low system requirements, unlike, for example, the software product "Supermag +".

3) Innovation and openness for integration with software of various developers (1C: Enterprise, SAP, "Supermag +", etc.).

4) System expansion is the ability to maximize the use of all user interfaces without involving a developer. Like Excel and more: group, filter, order, upload, customize, copy / paste, apply / undo. Third-party intervention in the program algorithm is allowed, unlike, for example, the "Galaxy" program.

5) Competitive price. License for one workplace of the software product "Galaxy" is 350-1200 US dollars, "1C: Enterprise" is 150-600 US dollars, Ls Fusion ERP Trading System is about 500 US dollars (according to the relevant sites and experts).

So, the benefits to a business from using the Ls Fusion ERP trading system are as follows: unification, versatility, cloud technologies, integration with software, system expansion, additional capabilities in our own developments, competitive price. They allow solving the following tasks of automating business processes using this program:

- implementation of operational accounting and control over the state of stocks in retail outlets;

- increasing the efficiency of sales;

- reduction of losses;

- analysis of purchases and sales by product groups and goods.
Thus, there is a compliance of the Ls Trade Fusion ERP software product with the requirements for integrated automation systems of a trade organization according to functional criteria; reflecting the specifics of the business; the ability to obtain complete and versatile reporting; continuity of data from old systems. Obviously, the introduction of a single software product in consumer cooperation organizations (avoiding their diversity) and, thus, the creation of a system for complex automation of business processes, requires financial investments, training of personnel of organizations.

Assessment of the implementation of the strategy implementation plan is the final stage of monitoring.

The implementation of the strategy for automating business processes started with the automation of stores of the Grodno consumer society. In 2020, more than 60 retail facilities in Minsk and Grodno regions were automated. As of January 1, 2021, 777 trade objects are equipped with special computer-cash systems for accounting for goods movement. The implementation process covers all regional divisions of Belcoopsoyuz. The number of retail outlets includes car dealerships.

In 2021, 867 objects are planned for automation. The total number of retail outlets subject to automation is 2,774 .

Meanwhile, in mid-2021, 273 retail facilities were automated (33\% of the annual target) and 52 warehouses in trade distribution warehouses (18\% of their total number). So, the schedule of automation of shopping facilities is not fully implemented, which indicates insufficient effectiveness of automation of business processes of consumer cooperation organizations.

The results of automation monitoring serve to justify management decisions. In this case, such a decision may be a recommendation to the heads of regional demand unions, regional demand communities to make changes to the automation schedules for 2021, taking into account the introduction of electronic document management of goods subject to labeling; ensure the implementation of the updated schedules for the automation of the trading network; to provide step-by-step automation of business processes in all sectors of activity of consumer cooperation organizations (trade, procurement, industrial, catering).

It is advisable for the management of the unitary enterprise "Computing Center of Belcoopsoyuz" to develop a strategy for the stage-by-stage automation 
of business processes in all sectors of activity of consumer cooperation organizations (trade, procurement, industrial, catering); to ensure the automation of the retail network in accordance with the schedules of regional consumer unions, regional needs of societies.

\section{DISCUSSION}

The study showed that consumer cooperation trade in Belarus, implementing a strategy for automating its business processes, generally follows the generally accepted rules for implementing strategies. There is a plan for the implementation of the strategy in the form of targets, the implementation of the plan for the implementation of the strategy is monitored and evaluated, the goals, strategies and plans are communicated to employees in order to involve them in the process of implementing the strategies, the achievement of goals is fixed.

However, the success of the implementation of the automation strategy is determined by the timeliness of receipt of all material, financial and labor resources necessary for its implementation. It is with this rule, as the approbation of the monitoring stages has shown, that the insufficient effectiveness of the automation of business processes of cooperative trade organizations is primarily associated. Thus, one should return to the stage of goal-setting and clarify the target settings of the strategic plan of measures for automating business processes, bringing them in line with the state and forecast of material, financial and labor resources.

\section{CONCLUSION}

The study made it possible to substantiate the following sequence of stages for monitoring the implementation of a strategy for automating business processes of trade organizations:

- establish the existence of a plan for the implementation of the strategy in the form of targets (plan, program, concept for the development of the organization);

- track compliance with the requirements for the integrated automation system of the organization through the solution of the following tasks: demonstration of the functional purpose of the software product; justification of the business benefits from using a software product;
- determine the communication of goals, strategies and plans to employees in order to involve them in the process of implementing strategies (the presence of resolutions, orders, orders);

- establish the fixation of the achievement of the goal (reports of organizations);

- assess the timeliness of ensuring the receipt of all the resources necessary for the implementation of the strategy (explanations of the heads of organizations);

- determine the implementation of the plan for the implementation of the strategy for automating business processes based on the results of the analysis of the regulatory documents of organizations (analysis of reporting forms, resolutions, programs).

The article describes three tested stages of monitoring the implementation of a strategy for automating business processes in cooperative trade organizations in Belarus and analyzes the results. The most detailed reflection of these stages received the rationale for choosing the software product of the Ls Fusion ERP Trading System by assessing its compliance with the requirements for integrated automation systems of trade organizations. The advantages of Ls Fusion ERP were studied in detail and, in particular, the unification of business process management, which is relevant with the diversified nature of consumer cooperation organizations (trade, procurement activities, production, public catering).

Evaluation of the implementation of the strategy implementation plan, as the final stage of monitoring, demonstrates its effectiveness and shows the lag in the automation of business processes in trade enterprises of consumer cooperation in Belarus. One of the main reasons for the lag seems to be the insufficient provision of organizations with the resources necessary for the implementation of the strategy.

The practical significance of the study lies in the proof of the thesis on the need to monitor the implementation of a strategy for automating business processes in trade organizations, its applicability and feasibility. Monitoring materials increase the validity of corrective actions when necessary and serve to increase the level of achievability of the results outlined in the strategy.

The development of corrective measures should be correlated with the compliance of the target settings of the strategy with the resource capabilities 
of consumer cooperation. At the same time, it is important to forecast the development of the resource component, which seems to be one of the directions for further research of the issues considered here. It is also significant to study the possibilities of developing these resources themselves.

\section{AUTHORS' CONTRIBUTIONS}

Each of the authors made an equal contribution to the work, considering their research preferences. Oksana G. Bondarenko collected, processed, and analyzed primary information. The conceptualization of the article, the scientific and practical significance of its material, the conclusions and directions of further research are described by Vera T. Grishina and Vladimir A. Trifonov.

\section{REFERENCES}

[1] M.A. Izmailova, N.V. Rebrikova, O.V. Kolesnikova, N.S. Khoroshavina, O.A. Shalnova, "Major factors of achievement of quality of corporate management in the Russian medium-sized companies", Quality Access to Success, 2018, vol. 19(166), pp. 7280.

[2] O.S. Vikhanskiy, A.I. Naumov, "Management": Textbook, Moscow: Master: INFRA-M, 2014. (In Russ.).

[3] M.Y. Veselovsky, M.A. Izmailova, M.S. Abrashkin, V.T. Grishina, T.I. Zvorykina, "Problems of Innovational Development of Russian Regions in the Modern Economic Environment", International Journal of Economic Research, 2017, vol. 14(7), pp. 239-252.

[4] O.E. Ivanova, M.S. Abrashkin, V.T. Grishina, I.K. Zakharenko, "Modification of the Financial Security Database in Russian Industrial Organizations", Revista Inclusions, 2020, vol. 7, pp. 540-556.

[5] "Organization management" [Upravleniye organizatsiyey]: Textbook, In Eds. by
A.G. Porshneva, Z.P. Rumyantseva, N.A. Solomatina. Moscow: INFRA-M, 2000. (In Russ.).

[6] O.G. Bondarenko, V.T. Grishina, O.Z. Matveeva, "Conceptual draft of the strategy for the formation of an optimal integrated infrastructure for rural trade in Belarus", Fundamental and Applied Research Studies of the Economics Cooperative Sector, 2019, vol. 6, pp. 149-160. (In Russ.).

[7] Law of the Republic of Belarus "On Information, Informatization and Protection of Information" ["Ob informatsii, informatizatsii i zashchite informatsii”] No. 455-Z dated November 10, 2008. (In Russ.). Retrieved from https://kodeksy-

by.com/zakon_rb_ob_informatsii_informatizatsi i_i_zawite_informatsii.htm

[8] Ju.V. Gnezdova, N.S. Khoroshavina, N.E. Lebedeva, I.V. Balynin, L.D. Sanginova, "The Impact of the Industry Digitization on the Economic Development of the Country", Journal Amazonia Investiga, 2019, vol. 8(21), pp. 633-643.

[9] M. Veselovsky, M. Šikýř, M. Abrashkin, “The Specifics of Development and Management of Innovative Infrastructure of Russian Industry", in Proceedings of the 11th International Days of Statistics and Economics, University of Economics, Prague, 2017, pp. 1740-1749.

[10] "Enterprise automation system" [Sistema avtomatizatsii predpriyatiy], NPO "LuxSoft" company, 2021. (In Russ.). Retrieved from https://luxsoft.by/o-kompanii-2/

[11] State. Business. IT [Tadviser Gosudarstvo. Biznes. IT], 2021. (In Russ.). Retrieved from www.tadviser.ru

[12]N.S. Khoroshavina, M.M. Kozirev, E.V. Kravets, "Transformation of the business model of reserve management under digitalization", The European Proceedings of Social \& Behavioural Sciences EpSBS, 2019, vol. 64 , pp. 519-526. 